Table 1. Comparison of data of patients with and without CNS involvement

\begin{tabular}{lccc}
\hline & CNS Involvement (+) & CNS Involvement (-) & \\
$\mathrm{n}(\%)$ & $\mathrm{n}: 24$ & $\mathrm{n}: 370$ & $\mathrm{P}$ \\
\hline Gender & & & 0.396 \\
$\quad$ Female & $8(33.3)$ & $164(44.3)$ & \\
$\quad$ Male & $16(66.7)$ & $206(55.7)$ & \\
Oral Aphthous Ulcer & $22(91.7)$ & $357(96.5)$ & 0.230 \\
Genital Ulcer & $17(70.8)$ & $239(64.6)$ & 0.661 \\
Papulopustular lesion & $9(37.5)$ & $120(32.4)$ & 0.655 \\
Erythema Nodosum & $11(45.8)$ & $139(37.6)$ & 0.516 \\
Pathergy & $11(45.8)$ & $174(47)$ & 0.988 \\
Uveitis & $9(37.5)$ & $129(34.9)$ & 0.827 \\
Retinal Vasculitis & $1(4.2)$ & $10(2.7)$ & 0.504 \\
Arthritis & $3(12.5)$ & $95(25.7)$ & 0.221 \\
Deep Venous Involvement & $6(25)$ & $59(15.9)$ & 0.256 \\
Artery Occlusion & $1(4.2)$ & $8(2.2)$ & 0.436 \\
Arterial Aneurysm & $1(4.2)$ & $14(3.8)$ & 1 \\
GIS involvement & $2(8.3)$ & $15(4.1)$ & 0.277 \\
Cardiac involvement & $2(8.3)$ & $4(1.1)$ & 0.046 \\
\hline
\end{tabular}

Conclusion: It has been reported that neurological symptoms occur in an average of 2.5 to 6.5 years after the diagnosis of BD. On the other hand, it has been stated that neurological complications may be the first involvement in 3-33\% of the cases and this situation will cause diagnostic difficulties ${ }^{1}$. These data are consistent with our study.

REFERENCES:

[1] Noel N, Drier A, Wechsler B, ve ark. Neurological manifestations of Behcet's disease. Rev Med Interne 2014;35(2):112-120.

Disclosure of Interests: None declared

DOI: 10.1136/annrheumdis-2021-eular.1365

\section{AB0360 1 A DECADE OF SUSPECTED GIANT CELL ARTERITIS: CLINICAL FEATURES OF A HIGHLY HETEROGENEOUS DISEASE}

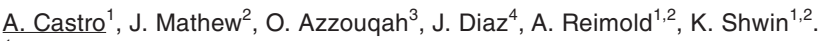
${ }^{1}$ UT Southwestern Medical Center, Rheumatology, Dallas, United States of America; ${ }^{2}$ Dallas VA Medical Center, Rheumatology, Dallas, United States of America; ${ }^{3}$ Presbyterian Rust Medical Center, Rheumatology, Rio Rancho, United States of America; ${ }^{4}$ Universidad de los Andes, Epidemiology, Bogotá, Colombia

Background: Giant cell arteritis is the most common chronic systemic vasculitis in older adults. Permanent visual loss is the most concerning complication can occur in up to $20 \%$ of patients (1). Diagnosis is based on a combination of clinical findings, laboratory evidence of inflammatory markers, and temporal artery biopsy (TAB) confirming histologic evidence of inflammation. There are no definitive markers of the disease when TAB is negative.

Objectives: The objective of this study was to illustrate the clinical features of subjects suspected with GCA evaluated at the Dallas Veterans Affairs Medical Center (VAMC) and identify those features that would differentiate between TAB positive GCA, TAB negative GCA and non-GCA patients.

Methods: This retrospective study searched the Dallas VAMC database for subjects between January of 2010 until December 2019 with ICD-9 and ICD10 entry code for GCA. Based on the 1990 ACR clinical classification criteria for GCA, suspected patients were classified as TAB positive GCA, TAB negative GCA and non-GCA. Subjects with incomplete data needed for classification were excluded. Group comparisons were performed with Fisher's exact test for categorical variables and the Mann-Whitney test for continuous variables.

Results: One-hundred and sixty-nine subjects had ICD-9/10 entry code for GCA. Ophthalmology was the specialty who did the initial evaluation in $46 \%$ of the suspected cases. Seventy-one patients were excluded due to incomplete data. Of the remaining 98 patients, $42(42.9 \%)$ were diagnosed with GCA out of which 10 patients had a positive TAB. Seventy-six percent of patients diagnosed with GCA had negative temporal artery biopsies. In 56 (57.1\%) patients GCA was ruled out (Figure 1). New-onset headache was the predominant symptom suggestive of GCA affecting $88.9 \%$ TAB positive and $100 \%$ of TAB negative cases compared to $56.6 \%$ of non-GCA patients ( $p<0.001$ ), followed by scalp tenderness in $33.3 \%, 58.1 \%$ and $10.9 \%$, respectively $(\mathrm{p}<0.001)$, jaw claudication in $57.1 \%, 34.5 \%$ and $14.9 \%(p=0.021)$, and elevated sedimentation rate in $33 \%$, $65.6 \%$ and $33 \%(p=0.013$ ) (Table 1). Polymyalgia rheumatica was present in $28.6 \%$ and $21.7 \%$ of patients diagnosed with GCA compared to zero percent in non-GCA cases $(p=0.017)$. More than $30 \%$ of patients with GCA had normal acute phase reactants in this cohort.

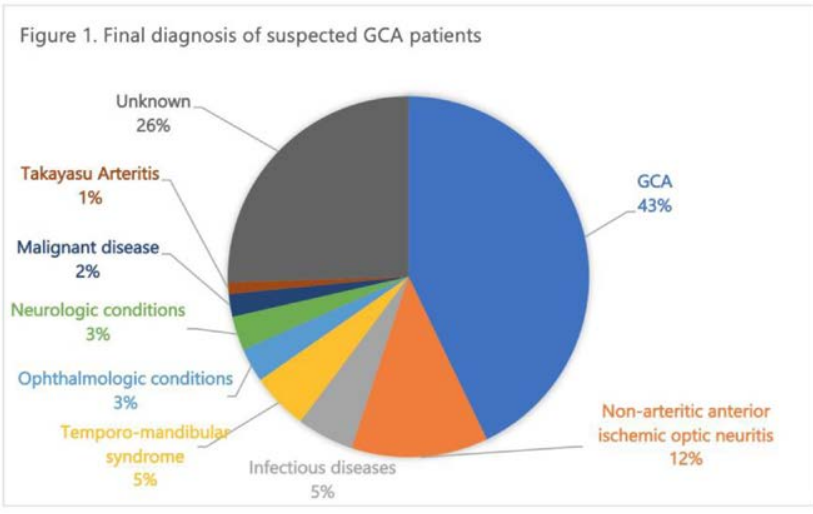

Table 1. Comparison of demographics and clinical features of patients with suspected GCA

\begin{tabular}{lcccccccc}
\hline & $\begin{array}{c}\text { GCA TAB } \\
\text { Positive } \\
(\mathbf{n}=\mathbf{1 0})\end{array}$ & $\begin{array}{c}\text { GCA - TAB } \\
\text { Negative } \\
(\mathbf{n}=\mathbf{3 2})\end{array}$ & $\begin{array}{c}\text { non-GCA } \\
(\mathbf{n}=56)\end{array}$ & \\
& $\mathbf{n}$ & $\%$ & $\mathbf{n}$ & $\%$ & $\mathbf{n}$ & $\%$ & $\mathbf{p}$ \\
\hline Age (mean/sd) & $71.3(7.8)$ & & $67.3(8.1)$ & & $67.3(8.9)$ & & 0.367 \\
Male & 9 & 90 & $30 / 32$ & 93.8 & $51 / 56$ & 91.1 & 0.885 \\
Clinical findings & & & & & & & \\
New onset headache & $8 / 9$ & 88.9 & $32 / 32$ & 100 & $30 / 53$ & 56.6 & $<0.001$ \\
Visual symptoms & $9 / 10$ & 90 & $22 / 32$ & 68.8 & $42 / 54$ & 77.8 & 0.351 \\
Jaw claudication & $4 / 7$ & 57.1 & $10 / 29$ & 34.5 & $7 / 47$ & 14.9 & 0.021 \\
PMR & $2 / 7$ & 28.6 & $5 / 23$ & 21.7 & $0 / 30$ & 0 & 0.017 \\
Scalp tenderness & $2 / 6$ & 33.3 & $18 / 31$ & 58.1 & $5 / 46$ & 10.9 & $<0.001$ \\
Fever & $0 / 5$ & 0 & $5 / 23$ & 21.7 & $2 / 35$ & 5.7 & 0.117 \\
ESR $>$ 50 & $1 / 3$ & 33.3 & $21 / 32$ & 65.6 & $18 / 54$ & 33.3 & 0.013 \\
CRP $>$ 10 & $1 / 3$ & 33.3 & $5 / 30$ & 16.7 & $6 / 54$ & 11.1 & 0.473 \\
Anemia (hemoglobin $<12 \mathrm{~g} / \mathrm{dl})$ & $2 / 7$ & 28.6 & $15 / 32$ & 46.9 & $21 / 52$ & 40.4 & 0.642 \\
Thrombocytosis (platelets $>400)$ & $2 / 7$ & 28.6 & $3 / 32$ & 9.4 & $4 / 51$ & 7.8 & 0.228 \\
\hline & & & & & & & \\
\hline & & & & & & & &
\end{tabular}

Conclusion: There is clinical heterogeneity within the patients diagnosed with GCA regardless of TAB. A high index of clinical suspicion needs to be the cornerstone of diagnosis. There is need for new classification criteria to include patients with negative TAB.

REFERENCES:

[1] Soriano A, et al. Nat Rev Rheumatol. 2017 Aug;13(8):476-484.

Disclosure of Interests: Adela Castro: None declared, Jiby Mathew: None declared, Ola Azzouqah: None declared, Jesus Diaz: None declared, Andreas Reimold Consultant of: Lilly, Grant/research support from: Abbvie

Pfizer

Gilead, Kyawt Shwin: None declared

DOI: 10.1136/annrheumdis-2021-eular.1461 